\title{
Preventive effect of ulinastatin on postoperative complications, immunosuppression, and recurrence in esophagectomy patients
}

\author{
Lingmin Zhang $^{1 \dagger}$, Ning Wang ${ }^{2 \dagger}$, Suna Zhou ${ }^{3}$, Wenguang $\mathrm{Ye}^{4}$, Qinglin Yao ${ }^{4}$, Guixia Jing ${ }^{{ }^{*}}$ and Mingxin Zhang ${ }^{4^{*}}$
}

\begin{abstract}
Background: To evaluate the potential efficacy of preventive effect of ulinastatin in esophagectomy patients.

Methods: Eighty patients with esophageal cancer were preoperatively allocated at random into two equal groups. Ulinastatin was administered to the treatment group $(U)$ whereas the control group $(C)$ received a placebo. The arterial oxygen tension and carbon dioxide tension were measured and the respiratory index (RI) was calculated. Plasma levels of circulating T lymphocyte subsets and interleukin 6 (IL-6) were measured and clinical courses of patients in the two groups were compared.

Results: $\mathrm{Rl}$ in the $\mathrm{U}$ group was significantly lower than that in the $\mathrm{C}$ group. The rate of postoperative complications and the duration of ICU stay were significantly lower in the $U$ group. Ulinastatin significantly increased the rate of $\mathrm{CD}^{+}$and $\mathrm{CD}^{+}$cells, and ratio of $\mathrm{CD}^{+} / \mathrm{CD}^{+}$, but decreased the rate of $\mathrm{CD} 8^{+}$cells and release of $\mathrm{IL}-6$ compared to the $C$ group on postoperative days 1 and 3 . Patients within the $C$ group showed worse recurrence free survival. Multivariate analysis revealed that ulinastatin administration significantly decreased the incidence of recurrence.

Conclusions: Ulinastatin had a preventive effect on postoperative complications and immunosuppression in esophagectomy patients, thereby prolongingrecurrence free survival.
\end{abstract}

Keywords: Esophagectomy, Immunosuppression, Postoperative complications, Recurrence, Ulinastatin

\section{Background}

Surgery remains the most effective treatment for solid tumors including esophageal cancer. However, esophagectomy, one of the most invasive procedures among gastrointestinal operations, has a high frequency of postoperative complications [1]. Several responsible background factors have been proposed to explain the broad spectrum of postoperative complications after such invasive procedures. The most important ones are systemic inflammatory response syndrome and compensatory anti-inflammatory cytokine response syndrome [2-4]. Moreover, surgical stress can cause immunosuppression in response to the complex interaction of various

\footnotetext{
*Correspondence: jgx666@126.com; zm×3115@163.com

${ }^{\dagger}$ Equal contributors

'Department of Anesthesiology, First Affiliated Hospital, Medical School,

Xi'an Jiaotong University, Xi'an 710061, Shaanxi Province, China

${ }^{4}$ Department of Gastroenterology, Tangdu Hospital, Fourth Military Medical

University, Xi'an 710038, Shaanxi Province, China

Full list of author information is available at the end of the article
}

hormones, cytokines, and acute phase reactants [5]. It has been reported that perioperative and postoperative immunosuppression increases the ratio of recurrence and adversely affects the prognosis of cancer patients $[6,7]$. Therefore, it is desirable to find an effective countermeasure against the overproduction of proinflammatory cytokines, postoperative complications, and immunosuppression.

Ulinastatin is a serine protease inhibitor with a molecular weight of $\sim 67,000$ found in healthy human urine. It is used worldwide for patients with inflammatory disorders, including disseminated intravascular coagulation, shock, and pancreatitis [8-10]. Furthermore, ulinastatin administration can help reduce the surgical stress, prevent radiation-induced lung injury, and modulate immune functions [11-13].

The aim of the present study was to evaluate the potential efficacy of preventive effect of ulinastatin on

\section{Biomed Central}

(c) 2013 Zhang et al.; licensee BioMed Central Ltd. This is an Open Access article distributed under the terms of the Creative Commons Attribution License (http://creativecommons.org/licenses/by/2.0), which permits unrestricted use, distribution, and reproduction in any medium, provided the original work is properly cited. 
postoperative complications, immunosuppression, and recurrence in esophagectomy patients.

\section{Methods}

\section{Patients}

Between January 2007 and December 2007, patients with lower thoracic esophageal cancer requiring surgical intervention at the First Affiliated Hospital and Second Affiliated Hospital, Medical College of Xi'an Jiaotong University, were enrolled. Exclusion criteria: prior chemotherapy or irradiation or immunosuppressive drug administration; blood loss $\geq 1,000 \mathrm{~mL}$; ASA classification $\geq$ III, histological type of adenocarcinoma. Eighty patients were subsequently randomized into two groups: control group $(C, n=40)$ and ulinastatin group $(U, n=40)$. The operative procedure for removal of the cancer was performed by a single surgical team and through the left posterolateral thoracotomy approach with combined thoracoabdominal lymphatic dissection, proximal gastric resection and mobilization of the stomach for esophageal replacement. Institutional Ethics Committee approval for this project was obtained. Written informed consent was obtained from each patient before randomization. The study was designed as a single blinded study. Ulinastatin (Miraclid, Mochida Pharmaceulinastatincal, Japan) was administered to the $U$ group as a bolus of 200,000 U diluted in $20 \mathrm{~mL}$ of normal saline every $24 \mathrm{~h}$ from 3 days pre-operation until 3 days post-operation.

\section{Clinical course evaluation}

Clinical course was evaluated based on rate of postoperative complications, including cardiovascular complications (arrhythmia, pulmonary embolism, and myocardial infarction), pulmonary complications (pneumonia, atelectasis, pulmonary edema), and others (esophagogastric anastomosis leakage, stenosis, and wound infection). The criteria of postoperative complications, especially for pulmonary complications, were described as before [14]. The duration of ICU and hospital stay was also determined. All patients received cisplatin-based postoperative adjuvant chemotherapy or standard radiotherapy, if required. The follow-up period ranged from 1 to 48 months (median, 35.7 months). Computed tomography (CT) was performed at least every 6 months to detect recurrence.

\section{Sample collection and assay}

Arterial blood was collected immediately at 10 minutes after operation began $\left(\mathrm{T}_{1}\right), 1$ hour after one-lung ventilation $\left(\mathrm{T}_{2}\right)$, and at the time of closure $\left(\mathrm{T}_{3}\right)$. Arterial oxygen tension $\left(\mathrm{Pa}_{\mathrm{O} 2}\right)$ and carbon dioxide tension $\left(\mathrm{Pa}_{\mathrm{CO}}\right)$ were measured by blood gas analysis. The respiratory index (RI) was calculated as a marker of lung damage using the following formulas: $R I=\left[F_{I O 2} \times(760-47)-P a_{C O} / 0.8\right] /$ $\mathrm{Pa}_{\mathrm{O} 2}$. Peripheral whole blood samples were obtained
Table 1 Baseline characteristics of the 80 patients

\begin{tabular}{llll}
\hline & $\begin{array}{l}\text { Control } \\
(\mathbf{n}=\mathbf{4 0})\end{array}$ & $\begin{array}{l}\text { Ulinastatin } \\
(\mathbf{n}=\mathbf{4 0})\end{array}$ & $\boldsymbol{P}$ \\
\hline Age & $56 \pm 12$ & $56 \pm 10$ & 0.861 \\
\hline Gender(male/female) & $34 / 6$ & $33 / 7$ & 0.762 \\
\hline TNM stage(I/I/III) & $7 / 18 / 15$ & $6 / 20 / 14$ & 0.897 \\
\hline Length of resection (cm) & $10 \pm 4.8$ & $11 \pm 4.0$ & 0.157 \\
\hline Number of lymph node dissection & $11 \pm 4.1$ & $10 \pm 4.6$ & 0.154 \\
\hline Alcohol consumption (yes/no) & $25 / 15$ & $23 / 17$ & 0.648 \\
\hline Smoker(yes/no) & $21 / 19$ & $20 / 20$ & 0.823 \\
\hline FEV1/FVC(\%) & $85.3 \pm 3.3$ & $85.1 \pm 4.3$ & 0.769 \\
\hline ASA classification (I/II) & $18 / 22$ & $17 / 23$ & 0.822 \\
\hline Duration of operation (min) & $206 \pm 44$ & $207 \pm 43$ & 0.918 \\
\hline Duration of anesthesia (min) & $240 \pm 46$ & $242 \pm 44$ & 0.862 \\
\hline Blood loss during operation (mL) & $520 \pm 43$ & $518 \pm 62$ & 0.903 \\
\hline
\end{tabular}

1 hour before surgery $\left(D_{0}\right)$ and on postoperative days 1,3 , and $7\left(D_{1}, D_{2}\right.$, and $\left.D_{3}\right)$. Lymphocyte subsets were counted by a FACSCalibur (Becton Dickinson, San Jose, CA, USA) flow cytometer. Cytokine levels (IL-6) were determined by ELISA, using commercially available kits (R\&D Systems, Minneapolis, MN, USA).

\section{Statistics}

Data are expressed as mean \pm standard deviation. Statistical analysis was performed with the SPSS software package (version 13.0, SPSS Institute). Continuous variables were analyzed using repeated measures ANOVA and categorical data were compared by the $x^{2}$ test or Fisher's exact test. Survival curves were estimated by the Kaplan-Meier method with the log-rank test. Multivariate analysis was performed using the Cox proportional hazard regression analysis. $P$ values $<0.05$ were considered significant.

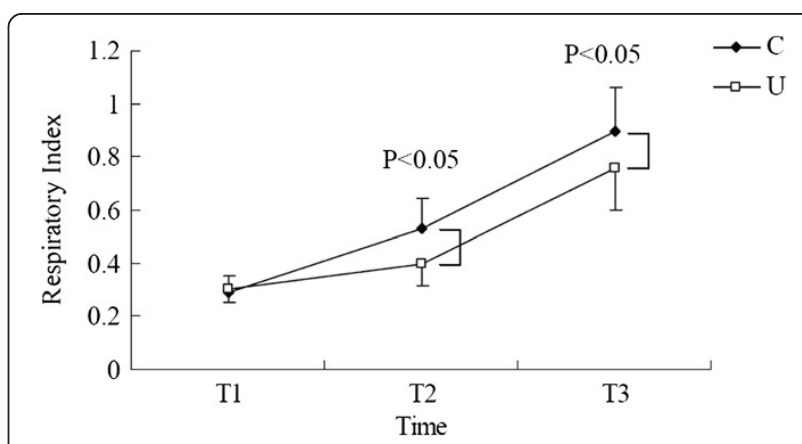

Figure 1 Effect of ulinastatin on respiratory index. Respiratory index (RI) in the ulinastatin group (U) was significantly lower than that in the control group (C) 1 hour after one-lung ventilation $\left(T_{2}\right)$ and the time of sternal closure $\left(T_{3} ; P<0.05\right)$. The $\mathrm{RI}$ was calculated as a marker of lung damage using the following formulas: $R I=\left[F_{1 O 2} \times(760-47)-P_{\mathrm{CO}_{2}} / 0.8\right] / \mathrm{Pa}_{\mathrm{O} 2}$. 
Table 2 Effect of ulinastatin on postoperative clinical course

\begin{tabular}{llll}
\hline & $\begin{array}{l}\text { Control } \\
(\mathbf{n}=\mathbf{4 0})\end{array}$ & $\begin{array}{l}\text { Ulinastatin } \\
(\mathbf{n}=\mathbf{4 0})\end{array}$ & $\boldsymbol{P}$ \\
\hline Cardiovascular complications & 1 & 1 & 1 \\
\hline Pulmonary complications & 8 & 1 & 0.034 \\
\hline Anastomosis leakage & 1 & 1 & 1 \\
\hline Anastomosis stenosis & 1 & 0 & 1 \\
\hline Wound infection & 1 & 1 & 1 \\
\hline Total & 12 & 4 & 0.034 \\
\hline Death & 1 & 0 & 1 \\
\hline Duration of ICU stay (hours) & $45 \pm 24$ & $33 \pm 16$ & 0.01 \\
\hline Length of hospital stay (days) & $11 \pm 4$ & $10 \pm 2$ & 0.170 \\
\hline
\end{tabular}

\section{Results}

\section{Baseline characteristics of enrolled patients}

During a period of 12 months between January 2007 and December 2007, 80 patients undergoing esophagectomy were enrolled in this study. Background factors for esophageal cancer patients are listed in Table 1. There were no significant differences between the groups in average age, gender, TNM stage, length of resection, number of lymph node dissection, alcohol consumption, smoking, ASA classification, duration of operation, duration of anesthesia, and blood loss during operation. Type of anesthesia was the same between the two groups. There were also no significant differences in perioperative management, including the usage of steroid and elastase inhibitor, infusion and nutritional support, and NSAIDs and other analgesics, between the two groups.

\section{Effect of ulinastatin on respiratory index}

RI before operation did not differ significantly between the groups (group U vs. C, $0.29 \pm 0.07$ vs. $0.31 \pm 0.06$ ), and there were significant time-dependent changes in RI value in both groups $(P<0.05$, Figure 1$)$. Group $\mathrm{U}$ showed significantly lower RI values than that of group $C$, both at 1 hour after one-lung ventilation $\left(\mathrm{T}_{2}\right)(0.40 \pm 0.09$
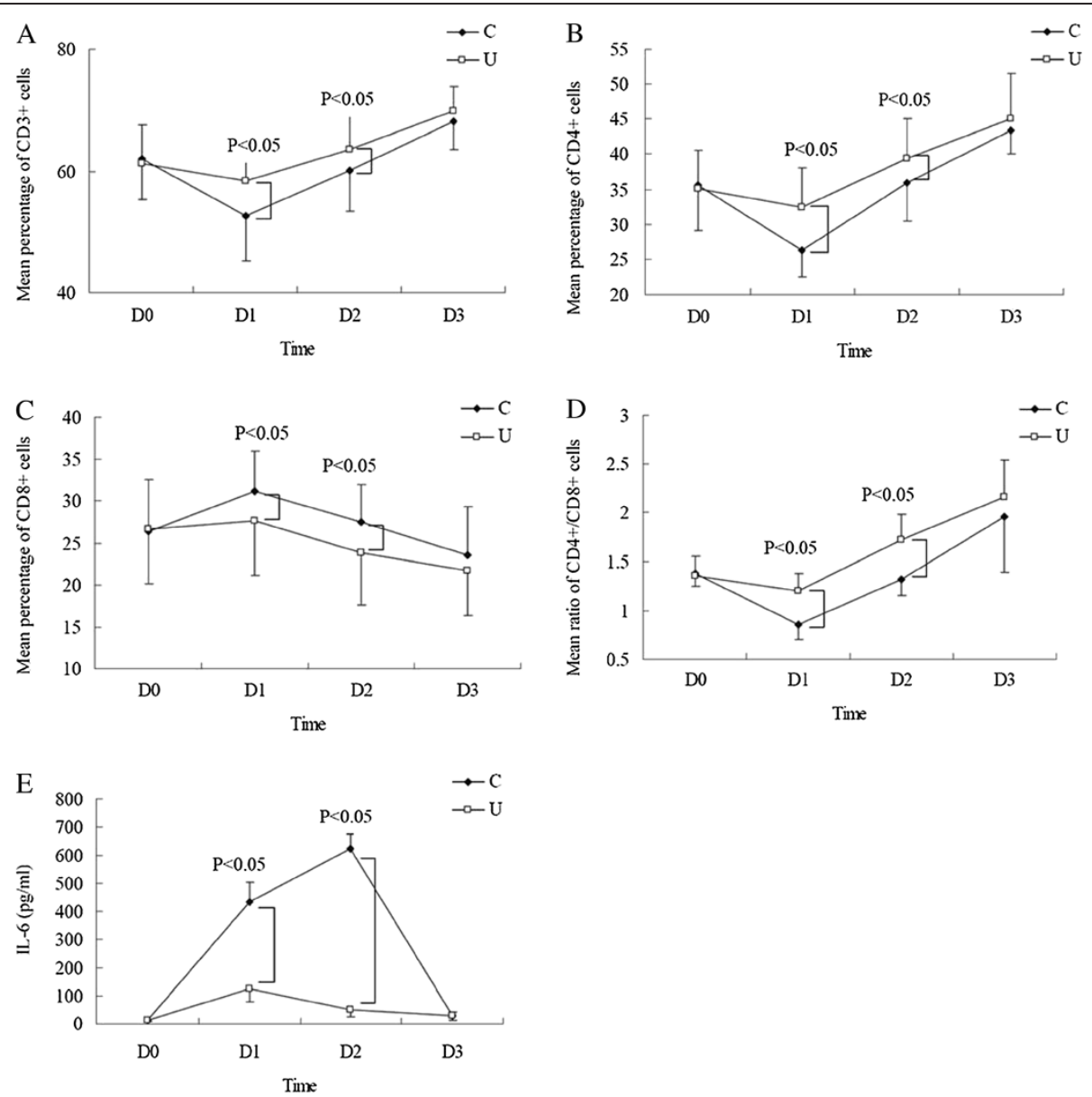

Figure 2 Effect of ulinastatin on lymphocyte subsets and IL-6. Ulinastatin $(U)$ administration significantly increased the rate of $C D 3^{+}(\mathbf{A})$ and $\mathrm{CD}^{+}(\mathbf{B})$ cells, and ratio of $\mathrm{CD}^{+} / \mathrm{CD}^{+}(\mathbf{D})$, but decreased the rate of $\mathrm{CD}^{+}(\mathbf{C})$ cells and release of IL-6 (E) compared to control group (C) on postoperative days $1\left(D_{1}\right)$ and $3\left(D_{2} ; P<0.05\right)$. $D_{0}=1$ hour before surgery, $D_{3}=$ Postoperative day 7 . 


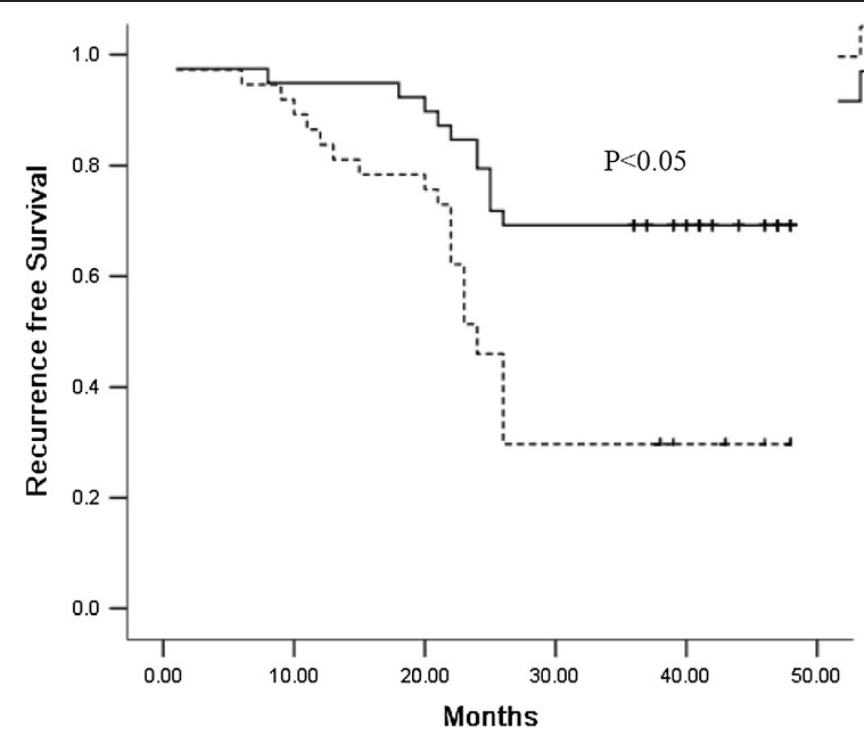

Figure 3 Kaplan-Meier survival analysis. Cumulative recurrence free survival differences between patients in the $C$ and $U$ groups. Patients within the $C$ group showed worse recurrence free survival. $P$ value was obtained using the log-rank test of the difference.

vs. $0.53 \pm 0.11, P<0.05)$ and the time of sternal closure $\left(\mathrm{T}_{3}\right)(0.75 \pm 0.16$ vs. $0.90 \pm 0.17, P<0.05)$.

\section{Effect of ulinastatin on postoperative clinical course}

The postoperative clinical course of each patient was carefully monitored daily, and complications were checked (Table 2). Postoperative complications were observed in 12 patients (30\%) in the $C$ group and 4 patients $(10 \%)$ in the $\mathrm{U}$ group, respectively $(P<0.05)$. A significant decrease in pulmonary complications was observed in the $\mathrm{U}$ group $(P<0.05)$, and one patient in the $C$ group died of pulmonary oedema. Although length of hospital stay showed no significant differences between the two groups, the duration of ICU stay was significantly shorter in the $U$ group $(P<0.05)$.

As can be seen from Figure 2, ulinastatin administration significantly increased the rate of $\mathrm{CD}^{+}$and $\mathrm{CD} 4^{+}$ cells, and ratio of $\mathrm{CD} 4^{+} / \mathrm{CD}^{+}$, but decreased the rate of $\mathrm{CD}^{+}$cells and release of IL- 6 compared to the $\mathrm{C}$ group on $\mathrm{D}_{1}$ and $\mathrm{D}_{2}(P<0.05)$.

\section{Side effects}

No patient experienced side effects related to ulinastatin administration; namely, shock, itching, rash, nausea, vomiting, or neutropenia.

\section{Survival analysis}

Of 80 patients in the database, one patient died in the $\mathrm{C}$ group during the perioperative period, and 3 were lost to follow-up. As a result, 76 patients were enrolled for survival analysis. The recurrence rate of the $\mathrm{U}$ group was $57.5 \%$ compared to $72.5 \%$ in the $C$ group. The most common recurrence pattern was locoregional recurrence
(60\% in the $\mathrm{U}$ group and $72 \%$ in the $\mathrm{C}$ group), while other patients developed systemic recurrence or a combination of both. Recurrence-free survival of all patients was $33.8 \pm 1.7$ months, and it was statistically better for the $\mathrm{U}$ group $(39.4 \pm 2.2)$ compared to the $\mathrm{C}$ group $(27.8 \pm 2.4)$ by Kaplan-Meier analysis $(P<0.05$, Figure 3$)$. Multivariate analysis revealed that ulinastatin administration significantly decreased the incidence of recurrence (Table 3).

\section{Discussion}

Major stressful surgery including esophagectomy always caused overproduction of proinflammatory cytokines. The initial proinflammatory response may be uncontrolled causing an imbalance between inflammatory response syndrome and compensatory anti-inflammatory cytokine response syndrome, which led to postoperative complications [15]. For the special surgical procedures, the risk of pulmonary complications after esophagectomy is higher than any other common operation [16]. Moreover, surgical stress can cause immunosuppression

Table 3 Multivariate cox proportional hazards analysis for recurrence free survival

\begin{tabular}{llll}
\hline Variables & \multicolumn{2}{l}{ Recurrence free survival } & $\boldsymbol{P}$ \\
\hline Ulinastatin administration & 0.149 & $95 \% \mathrm{Cl}$ & \\
\hline TNM & 1.812 & $0.063-0.351$ & $<0.05$ \\
\hline Alcohol consumption & 2.066 & $0.909-4.344$ & 0.754 \\
\hline Smoking & 1.088 & $0.534-2.217$ & 0.817 \\
\hline Gender & 0.916 & $0.425-1.973$ & 0.822 \\
\hline
\end{tabular}


in response to overproduction of proinflammatory cytokines. In esophageal cancer, a prognostic relation between the presence of complications and immunosuppression after esophagectomy and survival has previously been reported $[17,18]$. These data suggest that an effective countermeasure against postoperative complications and immunosuppression is desirable.

Ulinastatin has many physiological effects in surgical stress, including the decrease of the inflammatory reaction, inhibition of immunosuppression, and modification of the water balance $[13,19,20]$. Moreover, previous studies have shown that ulinastatin inhibits human ovarian cancer and the effect could be related to downregulation of protein kinase $C$ [21]. Studies have also found that ulinastatin enhances the inhibitory effect of docetaxel in breast cancer by a mechanism consistent with the down-regulated expression of IL-6, IL-8, and TNF- $\alpha$ [22]. Since ulinastatin had a preventive effect on postoperative complications and immunosuppression, and might inhibit the growth of cancer cells, we chose it for the certain purpose.

$\mathrm{CD}^{+}, \mathrm{CD}^{+}, \mathrm{CD} 8^{+}$T-lymphocyte percentage and $\mathrm{CD}^{+} / \mathrm{CD}^{+}$ratio were closely related to the cellular immune function and postoperative anti-tumor immunity [23-25]. Moreover, lower $\mathrm{CD}^{+}$, lower $\mathrm{CD}^{+}{ }^{+}$and lower $\mathrm{CD} 4^{+} / \mathrm{CD} 8^{+}$ratio were factors independently associated with worse prognosis of esophageal cancer patients in different reports $[26,27]$. Therefore, we investigated effect of ulinastatin administration on content of lymphocyte subsets.

In the present study, it was found that ulinastatin administration had a protective effect on pulmonary function by decreasing the increasing trend of RI during operation. As a result, the postoperative complications were lower than that in the $\mathrm{C}$ group, especially for pulmonary complications. Low occurrence of postoperative complications shortens the duration of ICU stay and decreased cost of care. Further, we investigated the effect of ulinastatin on release of IL-6 and content of lymphocyte subsets. The change of post-operative IL-6 and lymphocyte subsets reflected beneficial effects of ulinastatin on anti-inflammatory action, postoperative immunosuppression, and postoperative anti-tumor response. Finally, we observed that the U group had a longer recurrence free survival.

\section{Conclusions}

From these results we concluded that ulinastatin had a preventive effect on postoperative complications and immunosuppression in esophagectomy patients,thereby, prolonging recurrence free survival. The possible reason may be that the enhanced anti-tumor response inhibited tumor metastasis $[28,29]$. However,the detailed mechanism of action of ulinastatin should be further studied at the molecular biological level. Evaluation of a large number of cases is also necessary to assess the clinical usefulness of ulinastatin.

\section{Abbreviations}

IL-6: Interleukin-6; RI: Respiratory index.

\section{Competing interests}

The authors declare that they have no competing interests.

\section{Authors' contributions}

LM and NW participated in the design and conduction of experiments, data analysis, and final drafting and writing of the manuscript. LM, NW, SZ and WY all contributed to these experiments. GJ and $M Z$ were closely involved in research design and drafting of the final manuscript. All authors read and approved the final manuscript.

\section{Author details}

${ }^{1}$ Department of Anesthesiology, First Affiliated Hospital, Medical School, Xi'an Jiaotong University, Xi'an 710061, Shaanxi Province, China. ${ }^{2}$ Department of Anesthesiology, Second Affiliated Hospital, Medical School, Xi'an Jiaotong University, Xi'an 710061, Shaanxi Province, China. ${ }^{3}$ Department of

Radiotherapy, Tangdu Hospital, Fourth Military Medical University, Xi'an 710038, Shaanxi Province, China. ${ }^{4}$ Department of Gastroenterology, Tangdu Hospital, Fourth Military Medical University, Xi'an 710038, Shaanxi Province, China.

Received: 28 October 2012 Accepted: 26 March 2013 Published: 10 April 2013

\section{References}

1. Whooley BP, Law S, Murthy SC, Alexandrou A, Wong J: Analysis of reduced death and complication rates after esophageal resection. Ann Surg 2001 233:338-344.

2. Sato N, Koeda K, Ikeda K, Kimura Y, Aoki K, Iwaya T, Akiyama Y, Ishida K, Saito K, Endo S: Randomized study of the benefits of preoperative corticosteroid administration on the postoperative morbidity and cytokine response in patients undergoing surgery for esophageal cancer. Ann Surg 2002, 236:184-190.

3. Suda K, Kitagawa Y, Ozawa S, Saikawa Y, Ueda M, Abraham E, Kitajima M, Ishizaka A: Serum concentrations of high-mobility group box chromosomal protein 1 before and after exposure to the surgical stress of thoracic esophagectomy: a predictor of clinical course after surgery? Dis Esophagus 2006, 19:5-9.

4. Yamaguchi Y, Hihara J, Hironaka K, Ohshita A, Okita R, Okawaki M, Matsuura K, Nagamine I, Ikeda T, Ohara M, Hamai Y: Postoperative immunosuppression cascade and immunotherapy using lymphokineactivated killer cells for patients with esophageal cancer: possible application for compensatory anti-inflammatory response syndrome. Oncol Rep 2006, 15:895-901.

5. Khansari DN, Murgo AJ, Faith RE: Effects of stress on the immune system. Immunol Today 1990, 11:170-175

6. Ogawa K, Hirai M, Katsube T, Murayama M, Hamaguchi K, Shimakawa T, Naritake Y, Hosokawa T, Kajiwara T: Suppression of cellular immunity by surgical stress. Surgery 2000, 127:329-336.

7. Shakhar G, Ben-Eliyahu S: Potential prophylactic measures against postoperative immunosuppression: could they reduce recurrence rates in oncological patients? Ann Surg Oncol 2003, 10:972-992.

8. Masuda T, Sato K, Noda C, Ikeda KM, Matsunaga A, Ogura MN, Shimizu K, Nagasawa H, Matsuyama N, Izumi T: Protective effect of urinary trypsin inhibitor on myocardial mitochondria during hemorrhagic shock and reperfusion. Crit Care Med 2003, 31:1987-1992

9. Inoue K, Takano H, Yanagisawa R, Yoshikawa T: Protective effects of urinary trypsin inhibitor on systemic inflammatory response induced by lipopolysaccharide. J Clin Biochem Nutr 2008, 43:139-142.

10. Uemura K, Murakami Y, Hayashidani Y, Sudo T, Hashimoto Y, Ohge H, Sueda T: Randomized clinical trial to assess the efficacy of ulinastatin for postoperative pancreatitis following pancreaticoduodenectomy. J Surg Oncol 2008, 98:309-313.

11. Ono $S$, Aosasa $S$, Mochizuki H: Effects of a protease inhibitor on reduction of surgical stress in esophagectomy. Am J Surg 1999, 177:78-82. 
12. Bao P, Gao W, Li S, Zhang L, Qu S, Wu C, Qi H: Effect of pretreatment with high-dose ulinastatin in preventing radiation-induced pulmonary injury in rats. Eur J Pharmacol 2009, 603:114-119.

13. Sato N, Endo S, Kimura Y, Ikeda K, Aoki K, Iwaya T, Akiyama Y, Noda Y, Saito $K$ : Influence of a human protease inhibitor on surgical stress induced immunosuppression. Dig Surg 2002, 19:300-305.

14. D'Journo XB, Michelet P, Marin V, Diesnis I, Blayac D, Doddoli C, Bongrand P, Thomas PA: An early inflammatory response to oesophagectomy predicts the occurrence of pulmonary complications. Eur I Cardiothorac Surg 2010, 37:1144-1151.

15. Lin E, Lowry SF: Inflammatory cytokines in major surgery: a functional perspective. Intensive Care Med 1999, 25:255-257.

16. Ferguson MK, Durkin AE: Preoperative prediction of the risk of pulmonary complications after esophagectomy for cancer. J Thorac Cardiovasc Surg 2002, 123:661-669.

17. Lagarde SM, de Boer JD, ten Kate FJ, Busch OR, Obertop H, van Lanschot JJ: Postoperative complications after esophagectomy for adenocarcinoma of the esophagus are related to timing of death due to recurrence. Ann Surg 2008, 247:71-76.

18. Takagi K, Yamamori H, Morishima Y, Toyoda Y, Nakajima N, Tashiro T: Preoperative immunosuppression: its relationship with high morbidity and mortality in patients receiving thoracic esophagectomy. Nutrition 2001, 17:13-17.

19. Park JH, Kwak SH, Jeong CW, Bae HB, Kim SJ: Effect of ulinastatin on cytokine reaction during gastrectomy. Korean J Anesthesiol 2010, 58:334-337.

20. Sato A, Kuwabara Y, Shinoda N, Kimura M, Ishiguro H, Fujii Y: Use of low dose dopamine, gabexate mesilate and ulinastatin reduces the water balance and pulmonary complication in thoracic esophagectomy patients. Dis Esophagus 2005, 18:151-154.

21. Kobayashi H, Suzuki M, Tanaka Y, Hirashima Y, Terao T: Suppression of urokinase expression and invasiveness by urinary trypsin inhibitor is mediated through inhibition of protein kinase C- and MEK/ERK/ c-Jun-dependent signaling pathways. J Biol Chem 2001, 276:2015-2022.

22. Zhao X, Sun X, Gao F, Luo J, Sun Z: Effects of ulinastatin and docetaxel on breast tumor growth and expression of IL-6, IL-8, and TNF-a. J Exp Clin Cancer Res 2011, 30:22.

23. Uchida K, Kusuda T, Koyabu M, Miyoshi H, Fukata N, Sumimoto K, Fukui Y, Sakaguchi Y, lkeura T, Shimatani M: Regulatory T cells in type 1 autoimmune pancreatitis. Int I Rheumatol 2012, 2012:795026.

24. Yu WK, Li WQ, Li N, Li JS: Mononuclear histocompatibility leukocyte antigen-DR expression in the early phase of acute pancreatitis. Pancreatology 2004, 4:233-243.

25. Chen L, Linsley PS, Hellström KE: Costimulation of T cells for tumor immunity. Immunol Today 1993, 14:483-486.

26. Nozoe T, Maehara Y, Sugimachi K: Preoperative sorting of circulating $T$ lymphocytes in patients with esophageal squamous cell carcinoma: its prognostic significance. World J Gastroenterol 2005, 11:6689-6693.

27. Guo SJ, Lin DM, Li J, Liu RZ, Zhou CX, Wang DM, Ma WB, Zhang YH, Zhang SR: Tumor-associated macrophages and CD3-zeta expression of tumorinfiltrating lymphocytes in human esophageal squamous-cell carcinoma. Dis Esophagus 2007, 20:107-116.

28. Sheu BC, Hsu SM, Ho HN, Lin RH, Torng PL, Huang SC: Reversed CD4/CD8 ratios of tumor-infiltrating lymphocytes are correlated with the progression of human cervical carcinoma. Cancer 1999, 86:1537-1543.

29. Balkwill F: Cancer and the chemokine network. Nat Rev Cancer 2004, 4:540-550.

doi:10.1186/1477-7819-11-84

Cite this article as: Zhang et al:: Preventive effect of ulinastatin on postoperative complications, immunosuppression, and recurrence in esophagectomy patients. World Journal of Surgical Oncology 2013 11:84.

\section{Submit your next manuscript to BioMed Central and take full advantage of:}

- Convenient online submission

- Thorough peer review

- No space constraints or color figure charges

- Immediate publication on acceptance

- Inclusion in PubMed, CAS, Scopus and Google Scholar

- Research which is freely available for redistribution

Submit your manuscript at www.biomedcentral.com/submit 